CZASOPISMO INŻYNIERII LA¿OWEJ, ŚRODOWISKA I ARCHITEKTURY JOURNAL OF CIVIL ENGINEERING, ENVIRONMENT AND ARCHITECTURE

JCEEA, t. XXXIII, z. 63 (1/II/16), styczeń-marzec 2016, s. 259-266

\author{
Adam LIPHARDT ${ }^{1}$ \\ Piotr RADZISZEWSKI ${ }^{2}$ \\ Jan KRÓL ${ }^{3}$
}

\title{
METODA OCENY MIESZALNOŚCI LEPISZCZY W MIESZANKACH MINERALNO-ASFALTOWYCH Z DESTRUKTEM
}

\begin{abstract}
Wykorzystanie destruktu asfaltowego do produkcji mieszanek mineralnoasfaltowych wiąże się często z koniecznością poprawy właściwości zestarzonego lepiszcza zawartego w destrukcie. Metody projektowania mieszanek mineralnoasfaltowych zakładają idealne wymieszanie lepiszcza otaczającego ziarna destruktu ze świeżym lepiszczem dodawanym do mieszanki. Prowadzone obecnie badania wskazują jednak na niecałkowite mieszanie się obydwu lepiszczy. W pracy przedstawiono metodę pozwalającą ocenić stopień zmieszania lepiszczy w mieszankach $\mathrm{z}$ destruktem asfaltowym. Oceny mieszalności dokonuje się na podstawie badań poszczególnych warstw otoczki asfaltowej. W reometrze dynamicznego ścinania (DSR) wykonuje się badania lepiszcza takie jak zespolony moduł ścinania, kąt przesunięcia fazowego, moduł podatności oraz procentowe odkształcenie sprężyste. $\mathrm{W}$ pracy opisano procedurę przygotowania próbek mieszanki mineralno-asfaltowej i odzyskiwania lepiszcza do badań reologicznych. Próbki asfaltu do badań otrzymywano stosując metodę etapowej ekstrakcji. Zaproponowana metoda pozwala charakteryzować zmiany właściwości w poszczególnych obszarach warstwy lepiszcza otaczającego granulat asfaltowy. W celu weryfikacji przydatności zaproponowanej metody przedstawiono przykładowe wyniki badań zmian właściwości lepiszcza w zależności od grubości otoczki. Przeprowadzone dotychczas analizy porównawcze modułu zespolonego i kąta przesunięcia fazowego poszczególnych warstw otoczki asfaltowej z zastosowaniem zaprezentowanej metody wykazały, iż stanowi ona przydatne narzędzie do oceny mieszalności lepiszczy w mieszankach mineralno-asfaltowych z destruktem.
\end{abstract}

Słowa kluczowe: mieszalność lepiszczy, destrukt asfaltowy, recykling, etapowa ekstrakcja

\footnotetext{
${ }^{1}$ Autor do korespondencji/corresponding author: Adam Liphardt, Instytut Dróg i Mostów, Wydział Inżynierii Lądowej, Politechnika Warszawska, Al. Armii Ludowej 16, 00-637 Warszawa, (+48 22) 234-64-61, a.liphardt@il.pw.edu.pl

${ }^{2}$ Piotr Radziszewski, Instytut Dróg i Mostów, Wydział Inżynierii Lądowej, Politechnika Warszawska, Al. Armii Ludowej 16, 00-637 Warszawa, (+48 22) 234-64-72, p.radziszewski@il.pw.edu.pl

3 Jan Król, Instytut Dróg i Mostów, Wydział Inżynierii Lądowej, Politechnika Warszawska, Al. Armii Ludowej 16, 00-637 Warszawa, (+48 22) 234-56-74, j.krol@il.pw.edu.pl
} 


\section{Wstęp}

Wykorzystanie destruktu asfaltowego do produkcji mieszanek mineralnoasfaltowych wiąże się często z koniecznością poprawy właściwości zestarzonego lepiszcza zawartego w destrukcie [1]. Ilość destruktu asfaltowego w mieszance mineralno-asfaltowej wpływa na takie właściwości mieszanki jak zagęszczalność, sztywność, trwałość oraz określa ilość i właściwości świeżego lepiszcza, które należy wprowadzić do mieszanki $[2,3]$. Najczęściej metody projektowania mieszanek mineralno-asfaltowych zakładają idealne wymieszanie lepiszcza otaczającego ziarna destruktu ze świeżym lepiszczem dodawanym do mieszanki. Powszechnie stosowane metody projektowania mieszanek mineralnoasfaltowych $\mathrm{z}$ destruktem zakładają, że lepiszcze $\mathrm{w}$ takiej mieszance jest jednorodne. W Europie parametry lepiszcza powstałego ze zmieszania asfaltu zawartego $\mathrm{w}$ destrukcie $\mathrm{z}$ lepiszczem odświeżającym, takie jak penetracja i temperatura mięknienia, określa się na podstawie wzorów zawartych m.in. w załączniku A do normy europejskiej PN-EN 13108-1.

$$
\mathrm{T}_{\mathrm{R} \& \mathrm{~B} \text { mix }}=\mathrm{a} \times \mathrm{T}_{\mathrm{R} \& \mathrm{~B} 1}+\mathrm{b} \times \mathrm{T}_{\mathrm{R} \& \mathrm{~B} 2}
$$

gdzie: $T_{R \& B}$ mix - obliczona temperatura mięknienia lepiszcza $w$ mieszance zawierającej destrukt,

$\mathrm{T}_{\mathrm{R \& B} 1}$ - temperatura mięknienia lepiszcza odzyskanego $\mathrm{z}$ destruktu,

$\mathrm{T}_{\mathrm{R \& B} 2}$ - temperatura mięknienia lepiszcza dodanego,

a i b - proporcje wagowe lepiszcza w destrukcie asfaltowym (a) i dodanego lepiszcza (b) w mieszance $a+b=1$

$$
\mathrm{a} \lg \operatorname{pen}_{1}+\mathrm{b} \lg p e n_{2}=(\mathrm{a}+\mathrm{b}) \lg p e n_{\mathrm{mix}}
$$

gdzie: pen ${ }_{m i x}$ - obliczona penetracja lepiszcza w mieszance zawierającej destrukt,

pen $_{1}$ - penetracja lepiszcza odzyskanego z destruktu,

pen $_{2}$ - penetracja lepiszcza dodanego,

a i b - proporcje wagowe lepiszcza w destrukcie asfaltowym (a) i dodanego lepiszcza (b) w mieszance $a+b=1$

Opisany wzorami 1 i 2 sposób wyznaczania temperatury mięknienia i penetracji asfaltu jest słuszny w przypadku gdy lepiszcze zawarte w destrukcie asfaltowym oraz świeże lepiszcze dodane do mieszanki ulegną całkowitemu wymieszaniu. Ponadto wzory te są słuszne jedynie w przypadku gdy obydwa lepiszcza zaliczają się do asfaltów drogowych. W przypadku gdy co najmniej jedno lepiszcze jest modyfikowane np. polimerem, wynik obliczenia parametrów opisujących konsystencję może różnić się od wielkości zmierzonej. W rzeczywistości całkowite wymieszanie lepiszczy zachodzi jedynie w ograniczonej strefie kontaktu obydwu lepiszczy (rysunek 1), natomiast poza tą strefą zachodzi nakładanie się jednej warstwy asfaltu na drugą $[4,5]$. 
a)
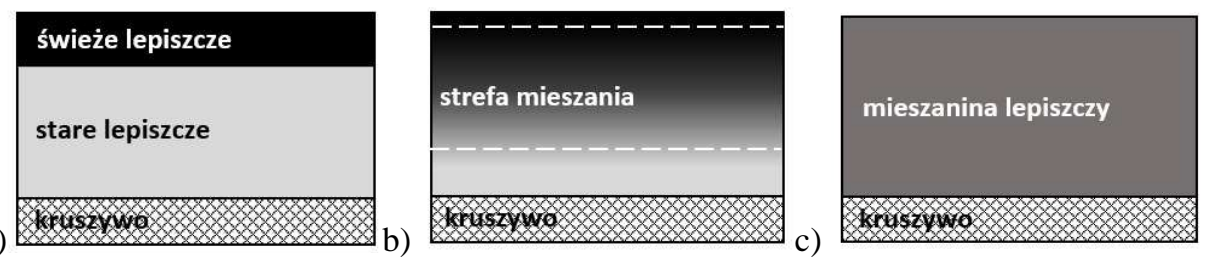

Rys. 1. Schemat mieszania lepiszczy w mieszankach z destruktem: a) brak mieszania, b) częściowe mieszanie, c) całkowite wymieszanie

Fig. 1. Binder blending scheme in mixtures with RAP: a) no blending, b) partial blending, c) complete blending

Sposób określania właściwości mieszaniny lepiszczy w mieszankach z destruktem na podstawie wzorów 1 i 2 wydaje się więc niewystarczający. W ciągu ostatnich lat badacze podejmują próby określenia stopnia zmieszania lepiszczy różnymi metodami. Są to zarówno metody bezpośrednie oparte w szczególności na analizie składu chemicznego lub mikrostruktury otoczki asfaltowej jak również metody pośrednie polegające m.in. na ocenie parametrów reologicznych lepiszcza otaczającego ziarna destruktu.

Wśród metod bezpośrednich wyróżnić można analizę spektrograficzną metoda FT-IR (ang. Fourier Transform Infrared Spectroscopy) pozwalającą m.in. na identyfikację produktów starzenia w mieszaninach asfaltów [6]. Metoda FTIR zastosowana została do oceny mieszalności lepiszczy w mieszankach $\mathrm{z}$ destruktem m.in. przez Bowersa i in. [7]. Inną metoda, polegającą z kolei na badaniu mikrostruktury mieszanin lepiszczy jest analiza obrazu uzyskanego z mikroskopu AFM (ang. Atomic Force Microscope) służąca m.in. do oceny rozmieszczenia cząstek polimeru w mieszaninie asfaltów [8].

Metody pośrednie polegają na analizie parametrów lepko-sprężystych pozwalających zróżnicować właściwości lepiszcza wyekstrahowanego z otoczki asfaltowej w mieszance. Najczęściej stosowanym w tego typu badaniach urządzeniem pomiarowym jest reometr dynamicznego ścinania DSR (ang. Dynamic Shear Rheometer) pozwalający ocenić m.in. takie właściwości jak zespolony moduł ścinania czy kąt przesunięcia fazowego. Pośredniej oceny mieszalności można również dokonać na podstawie wyników oznaczenia lepkości dynamicznej oraz podstawowych właściwości lepiszczy jak penetracja czy temperatura mięknienia.

Istotnym problemem występującym $\mathrm{w}$ ocenie mieszalności niezależnie od zastosowanych metod badawczych jest konieczność pozyskania próbek lepiszczy. Odzyskanie asfaltu z mieszanki mineralno-asfaltowej zawierającej destrukt przy zastosowaniu tradycyjnych metod ekstrakcji powoduje sztuczne ujednorodnienie lepiszcza [9]. Aby analizować zmiany właściwości lepiszcza na grubości błonki asfaltowej należy zastosować inną metodę odzyskiwania lepiszcza. 


\section{Metoda oceny mieszalności lepiszczy}

Pozyskanie próbek lepiszcza asfaltowego w sposób pozwalający na późniejszą ocenę zmienności jego parametrów na grubości otoczki asfaltowej umożliwia metoda etapowej ekstrakcji zaproponowana po raz pierwszy w 1980 roku przez Carpentera i Wolosicka [10]. Metoda polega na kilkukrotnym odmywaniu błonki lepiszcza począwszy od zewnętrznych warstw aż do całkowitego jej odmycia.

\subsection{Przygotowanie próbek}

Pierwszym etapem jest przygotowanie próbek mieszanki mineralnoasfaltowej z destruktem, które będą poddawane ekstrakcji. Mieszanka destruktu, ewentualnego kruszywa doziarniającego oraz świeżego lepiszcza przygotowywana jest w mieszalniku laboratoryjnym. Aby podczas ekstrakcji zapewnić jak najlepszy dostęp rozpuszczalnika do poszczególnych ziaren mieszanki musi być ona odpowiednio rozdrobniona. Po określonym założonym czasie mieszania mieszanka rozsypywana jest w cienkiej warstwie na płaskiej powierzchni pokrytej folią żaroodporną. Następnie, po całkowitym wystudzeniu do temperatury pokojowej tak rozsypana mieszanka umieszczana jest w komorze bębna Los Angeles i poddawana $100 \pm 3$ obrotom (bez użycia kul). Mieszanka ulega w ten sposób rozdrobnieniu na ziarna i grudki. $\mathrm{Z}$ rozdrobnionej mieszanki mineralnoasfaltowej metodą kwartowania pobierane są próbki do ekstrakcji.

\subsection{Etapowa ekstrakcja lepiszcza}

Zastosowana na Politechnice Warszawskiej metoda etapowej ekstrakcji polega na zanurzaniu próbki mieszanki mineralno-asfaltowej umieszczonej w koszu z siatki stalowej o oczku 0,6 $\mathrm{mm}$ w naczyniu z rozpuszczalnikiem (rysunek 2a). Do rozpuszczania asfaltu stosowany jest toluen ze względu na najmniejszy wpływ na zmiany właściwości asfaltu w stosunku do innych rozpuszczalników [11]. Próbka mieszanki zanurzana jest w rozpuszczalniku na ok. 15 sekund po czym jest wyjmowana i umieszczana w kolejnym naczyniu z czystym rozpuszczalnikiem. Czynności te powtarzane są od trzech do pięciu razy, w zależności od zakładanej ilości analizowanych warstw. Odmywanie ostatniej warstwy trwa do momentu całkowitego usunięcia otoczki asfaltowej z ziaren kruszywa.

Otrzymany w ten sposób roztwór asfaltu poddawany jest odwirowaniu w wirówce ekstrakcyjnej w celu odseparowania drobnych frakcji kruszywa mineralnego. Następnie zawarty w nim rozpuszczalnik odparowywany jest w wyparce próżniowej zgodnie z procedurą opisaną w normie PN-EN 12697-3 (rysunek $2 b$ ). Po odparowaniu rozpuszczalnika kolba z materiałem z każdej kolejnej warstwy jest ważona $w$ celu określenia procentowego udziału lepiszcza $z$ danej warstwy w stosunku do całkowitej zawartości lepiszcza w badanej mieszance mineralno-asfaltowej. 
a)

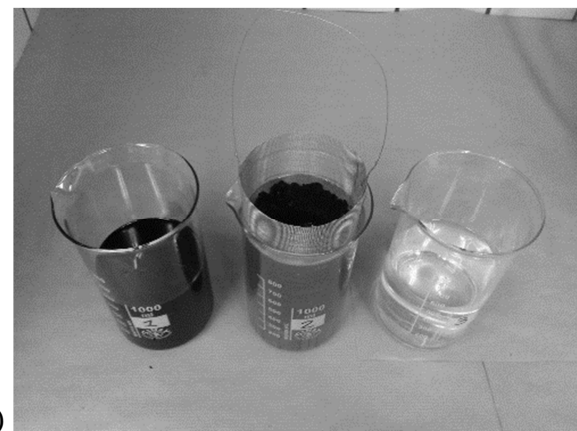

Rys. 2. Odzyskiwanie asfaltu: a) etapowa ekstrakcja, b) odparowywanie rozpuszczalnika w wyparce obrotowej

Fig. 2. Binder recovery: a) staged extraction, b) rota vapor - solvent evaporation

\subsection{Badania lepiszczy odzyskanych}

Lepiszcze asfaltowe odzyskane z poszczególnych faz odmywania poddawane jest badaniom $w$ reometrze dynamicznego ścinania. Wyznaczany jest zespolony moduł ścinania oraz kąt przesunięcia fazowego lepiszcza z każdej warstwy. Ponadto w przypadku, gdy któryś z asfaltów jest lepiszczem modyfikowanym polimerami można wykonać badanie zgodnie z procedurą cyklicznego pełzania z odprężeniem - MSCR (ang. Multiple Stress Creep Recovery Test) pozwalającą zróżnicować warstwy lepiszcza pod względem nawrotu sprężystego R i modułu podatności $J_{N R}[12]$. Procedura badania MSCR została dokładniej opisana w pracy [13].

\section{Wyniki badań}

Skuteczność opisywanej metody została zweryfikowana w badaniach przeprowadzonych na mieszance mineralno-asfaltowej zawierającej $100 \%$ destruktu pochodzącego z warstwy ścieralnej z mieszanki typu SMA oraz dodatku miękkiego lepiszcza o penetracji 100/150. Na rysunku 3a przedstawiono wykres zmienności zespolonego modułu ścinania natomiast na rysunku $3 \mathrm{~b}$ zmienność kąta przesunięcia fazowego poszczególnych warstw otoczki asfaltowej zbadanych w temperaturze $64^{\circ} \mathrm{C}$ przy częstości kątowej wynoszącej $10 \mathrm{rad} / \mathrm{s}$. Podczas badania tak dobierano czasy ekstrakcji żeby po przeliczeniu ilości wyekstrahowanego lepiszcza grubość poszczególnych odmywanych warstw była porównywalna. Na obydwu wykresach linią ciągłą zaznaczony został poziom właściwości odpowiadający pełnemu wymieszaniu obydwu lepiszczy. W pełni wymieszane lepiszcze uzyskano z ekstrakcji całej grubości otoczki w jednym cyklu odmywania. Założono, że lepiszcze uległo pełnemu wymieszaniu i ujednorodnieniu w procesie ekstrakcji i odzyskiwania. 


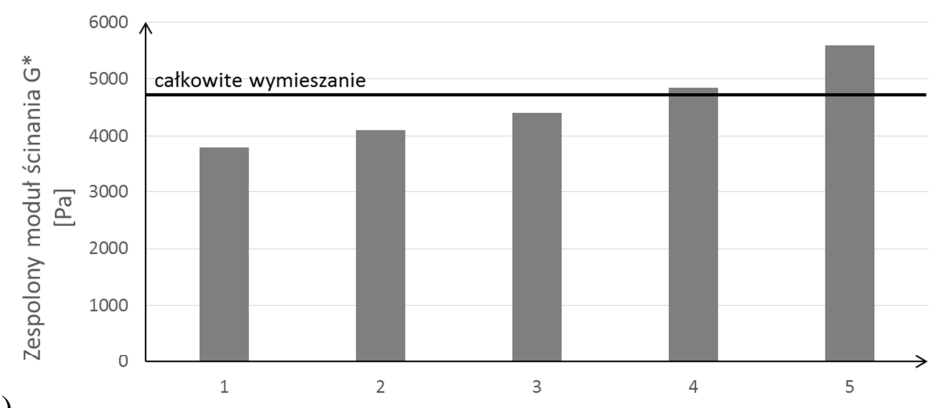

a)

Warstwa lepiszcza

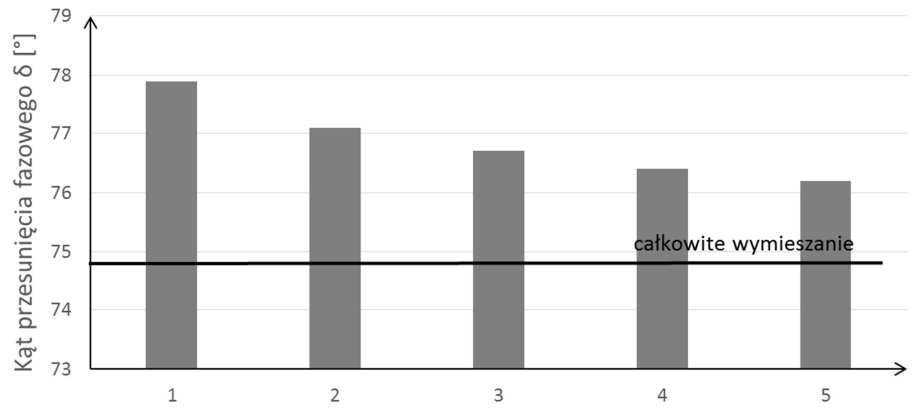

b)

Warstwa lepiszcza

Rys. 3. Właściwości lepko-sprężyste lepiszcza w poszczególnych warstwach otoczki asfaltowej: a) moduł zespolony $G^{*}$, b) kąt przesunięcia fazowego $\delta$, numerem 1 oznaczono warstwę zewnętrzną, numerem 5 warstwę wewnętrzną

Fig. 3. Viscoelastic properties of separate bituminous binder films: a) complex modulus $G^{*}$, b) phase angle $\delta$, number 1 represented external layer, number 5 represented internal layer

Ocena przedstawionych wyników pozwala stwierdzić, że właściwości lepiszcza otaczającego ziarna mieszanki mineralno-asfaltowej $\mathrm{z}$ destruktem są zmienne na grubości otoczki lepiszcza. Należy zaznaczyć, że w pewnym stopniu zmienność właściwości otoczki asfaltowej na jej grubości może być powodowana innym rozmieszczeniem struktur molekularnych w warstwie bezpośrednio otaczającej kruszywo niż w warstwach oddalonych od powierzchni ziarna [14]. Uzyskane wyniki potwierdzają, że metoda etapowej ekstrakcji umożliwia wyselekcjonowanie próbek lepiszcza do oceny mieszalności.

\section{Podsumowanie}

Przeprowadzone dotychczas badania i analizy pozwalają na sformułowanie następujących wniosków ogólnych:

- metoda etapowej ekstrakcji pozwala na wyselekcjonowanie próbek lepiszcza do badań charakteryzujących zmienność właściwości otoczki asfaltowej, 
- przeprowadzone dotychczas oznaczenie zespolonego modułu ścinania i kąta przesunięcia fazowego poszczególnych warstw otoczki asfaltowej z zastosowaniem zaprezentowanej metody wykazały, iż może ona stanowić przydatne narzędzie do oceny mieszalności lepiszczy w mieszankach mineralnoasfaltowych z destruktem,

- wyniki wstępnych badań wykonanych na Politechnice Warszawskiej wykazały zróżnicowanie właściwości asfaltu na grubości otoczki w mieszankach mineralno-asfaltowych destruktem co potwierdza, iż nie następuje całkowite wymieszanie obydwu lepiszczy.

W dalszej kolejności planuje się zastosowanie przedstawionej metody w badaniach mieszalności $\mathrm{z}$ wykorzystaniem kilku destruktów asfaltowych o zróżnicowanych właściwościach oraz różnych rodzajów lepiszczy odświeżających w celu identyfikacji zależności funkcyjnych pomiędzy właściwościami lepiszczy poddawanych mieszaniu a charakterystyką uzyskiwanych mieszanin w otoczce asfaltowej.

\section{Literatura}

[1] Piłat J., Radziszewski P.: Nawierzchnie asfaltowe. WKŁ, Warszawa 2010.

[2] Król J., Włodarski P., Jackowski Ł. Właściwości mieszanek mineralno-asfaltowych ze zwiększoną ilością granulatu asfaltowego, Drogownictwo, nr 11, 2014, s. 373-379.

[3] Kowalski K.J., McDaniel R.S., Olek J., "Reclaimed Asphalt Pavement Limits to Meet Surface Frictional Requirements", Journal of Materials in Civil Engineering, American Society of Civil Engineers (ASCE), vol. 28, 2016.

[4] Kriza P., Granta D. L., Velozab B. A., Galea M. J., Blaheya A. G., Browniea J. H., R. Shirtsc D., Maccarrone S.. Blending and diffusion of reclaimed asphalt pavement and virgin asphalt binders. Road Materials and Pavement Design, nr 15, 2014, 78-112.

[5] Yousefi R. F. Estimating Blending Level of Fresh and RAP Binders in Recycled Hot Mix Asphalt. Thesis. University of Wisconsin Madison (2013).

[6] Zofka A., Maliszewska D., Maliszewski M. Zastosowanie Techniki FT-IR w badaniach materiałów asfaltowych. Budownictwo i Architektura nr 13, 2014, 317-324.

[7] Bowers B. F., Huang B., Shu X., Miller B. C. Investigation of Reclaimed Asphalt Pavement blending efficiency through GPC and FTIR. Construction and Building Materials, nr 50, 2014, s. 517-523.

[8] Nahar S.N., Mohajeri M., Schmets A.J.M., Scarpas A., Van de Ven M. F. C., Schitter G. First observation of the blending zone morphology at the interface of reclaimed asphalt binder and virgin bitumen.

[9] Błażejowski K. Mieszanki z destruktem asfaltowym. Mieszalność lepiszczy. Konferencja Zastosowanie Destruktu Asfaltowego, Ożarów Mazowiecki 22-24 września 2010.

[10] Carpenter S. H., Wolosicka J. R.. Modifier influence in the characterization of hotmix recycled material. Transportation Research Record, 777, (1980) s. 15-22.

[11] Sybliski D., Horodecka R., Wrobel A., Bańkowski W., Mirski K. Badania właściwości lepiszcza asfaltowego odzyskanego z mieszanki mineralno-asfaltowej w celu oceny wiarygodności metody ekstrakcji i destylacji. Sprawozdanie z zadania TN-227, 2004.

[12] Liphardt A., Radziszewski P., Król J., Binder Blending Estimation Method in Hot Mix Asphalt with Reclaimed Asphalt, Procedia Engineering, Vol. 111, 2015, 502-509. 
[13] Król J., Matraszek K. Właściwości wysokotemperaturowe lepiszczy asfaltowych w badaniu cyklicznego pełzania z odprężeniem (MSCR), Drogownictwo, nr 10, 2012, 321-324.

[14] Iwański M., Adsorpcja asfaltu przez kruszywo w mieszance mineralno-asfaltowej, Drogownictwo, nr 9, 2012, 290-296.

\title{
BINDER MISCIBILITY EVALUATION METHOD FOR ASPHALT MIXTURES WITH RECLAIMED ASPHALT PAVEMENT
}

\begin{abstract}
S u m m a r y
The use of reclaimed asphalt pavement to produce asphalt mixtures require the refresh of the aged binder properties. Asphalt mixtures designing methods assume the total mixing of the binder from RAP and the added fresh binder. Research of many scientific institutes show that blending between both binders is not complete. The paper presents the method to assess the degree of mixing binders in mixtures with RAP. The assessment is based on the research of individual layers of binder film. Dynamic shear rheometer DSR is used to test binder properties such as a complex modulus, phase angle, no-recoverable creep compliance and elastic recovery. The paper describes the procedure for hot mix asphalt sample preparation and binder recovery for rheological testing. To prepare the samples for test were used staged extraction method. Changes of the properties of the individual areas of the binder layer surrounding the grain of RAP can be characterized using presented method. The paper also includes examples of the results of preliminary tests conducted in order to verify the usefulness of the presented method. Results of laboratory tests of complex modulus and phase angle and comparative analysis of these properties from individual layers of binder film showed that presented method is the useful device to evaluation the binder blending in hot mix asphalt with RAP.
\end{abstract}

Keywords: binder miscibility, reclaimed asphalt pavement, recycling, staged extraction

Przestano do redakcji: 07.06.2016 $r$.

Przyjęto do druku: 30.06 .2016 r.

DOI: $10.7862 / \mathrm{rb} .2016 .83$ 